\title{
Postnatal Generation of Neurons in the Ventrobasal Nucleus of the Rat Thalamus
}

\author{
Sandra M. Mooney ${ }^{1,2}$ and Michael W. Miller ${ }^{1,2,3}$ \\ ${ }^{1}$ Department of Neuroscience and Physiology, State University of New York-Upstate Medical University, Syracuse, New York 13210, ${ }^{2}$ Developmental \\ Exposure Alcohol Research Center, Binghamton, New York 13902 and Syracuse, New York 13104, and ${ }^{3}$ Research Service, Veterans Affairs Medical Center, \\ Syracuse, New York 13210
}

\begin{abstract}
Most CNS systems, including the trigeminal-somatosensory system, develop via a hierarchical order (from the periphery and up the neuraxis). We tested the hypothesis that development of the trigeminal system can proceed via a nonhierarchical mechanism (i.e., that neuronogenesis can occur postnatally). Preweanling rats were perfused, and brain sections were stained with cresyl violet or immunolabeled with NeuN (for neuronal counts), or processed for acetylcholinesterase (AChE) activity or p75 immunoreactivity [to identify boundaries of the ventrobasal nucleus (VB)]. Neuronal number decreased during the first postnatal week but increased 2.5-fold over the next 3 weeks. To determine whether this remarkable rise resulted from the generation of new neurons, preweanlings were given injections of bromodeoxyuridine (BrdU) on postnatal day 6 (P6) or P21. BrdU-positive VB cells were apparent on both days. Cumulative BrdU labeling showed that the cell cycle was $17.3 \mathrm{~h}$ on P6. Moreover, Ki-67, a protein elaborated throughout the cell cycle, was expressed by 25.8-29.3\% of all VB cells on P6-P15, falling to 7.7\% by P21. BrdU-positive VB cells coexpressed neuronal markers: NeuN, HuC/D, microtubule-associated protein 2, and a dextran placed in the somatosensory cortex. Note that postnatal neuronal generation was also evident in other thalamic nuclei (e.g., the lateral geniculate nucleus). Thus, the developing VB experiences two periods of neuronal generation. Prenatal neuronogenesis is part of hierarchical trigeminal-somatosensory development. Postnatal nonhierarchical neuronogenesis is intrathalamic and matches changes in neuromodulatory systems (exemplified by AChE activity and p75) and the arrival of corticothalamic afferents.
\end{abstract}

Key words: bromodeoxyuridine; lateral geniculate nucleus; neural stem cells; neurogenesis; proliferation; acetylcholinesterase (AchE)

\section{Introduction}

Development of components of the trigeminal-somatosensory system proceeds in a hierarchical order (i.e., up the neuraxis). This order is evident in the sequence of neuronogenesis. In the rat, most second-order neurons in the principal sensory nucleus of the trigeminal nerve (PSN) and spinal trigeminal nuclei are generated between gestational day 12 (G12) and G14 (Nornes and Morita, 1979; Altman and Bayer, 1980; Miller and Muller, 1989). Third-order neurons in the ventrobasal nucleus of the thalamus (VB) are generated on G14 and G15 (Altman and Bayer, 1989), and fourth-order neurons in layer IV of the somatosensory cortex, the primary target of afferents from the VB, are born on G17 and G18 (Miller, 1988). Like neuronogenesis, death of postmigratory neurons proceeds hierarchically. It peaks in the PSN, VB, and cortex neonatally (Ashwell and Waite, 1991; Miller and Al-Ghoul, 1993; Miller, 1999), during the middle of

\footnotetext{
Received June 16, 2005; accepted March 22, 2007.

This work was supported by the Department of Veterans Affairs and by National Institute of Alcohol Abuse and Alcoholism Grants AA06916 and AA07568 (M.W.M.), and AA015413 (S.M.M.). We gratefully thank Renee Mezza for assistance with the immunohistochemistry and Julie Siegenthaler for help in generating the confocal microscopy images.

Correspondence should be addressed to Dr. Sandra M. Mooney, Department of Neuroscience and Physiology, State University of New York-Upstate Medical University, 750 East Adams Street, Syracuse, NY 13210. E-mail: mooneys@upstate.edu.

DOI:10.1523/JNEUROSCI.1194-07.2007

Copyright $\odot 2007$ Society for Neuroscience $\quad$ 0270-6474/07/275023-10\$15.00/0
}

the first postnatal week (Waite et al., 1992; Mai et al., 1998), and at the end of the first postnatal week (Finlay and Slattery, 1983; Ferrer et al., 1990; Miller, 1995; Miller and Kuhn, 1997), respectively.

Overlap in the timing within each stage of development of trigeminal-somatosensory components allows for feedforward passage of information (e.g., the thalamus affects cortical development via ingrowth of thalamocortical axons). One advantage of this hierarchical pattern is the matching of neuronal numbers among components of the system (Wetts and Herrup, 1983). That is, the number of VB neurons is matched to the number in the brainstem, and cortical neuronal numbers are matched to the number of VB neurons.

Interestingly, some systems (e.g., olfactory and hippocampal) have a nonhierarchical aspect to their development. In these structures, proliferating neural stem cells (NSCs) produce neurons that are continually integrated into the adult system (Schlessinger et al., 1975, 1978; Hinds and McNelly, 1977, 1981; Miller, 1995; Kempermann et al., 1996; Luskin, 1998; Kornack and Rakic, 1999, 2001a). Apparently, these new neurons are critical for maintaining neural plasticity. The development of the visual pathway also exhibits a nonhierarchical component (Fitzgibbon, 2006). The perigeniculate nucleus matures before its afferent sources and its target.

Neuromodulatory systems are expressed during postnatal VB 
development. These include serotonin (Fujimiya et al., 1986; Bennett-Clarke et al., 1991; Bruning and Liangos, 1997), glutamate (Spreafico et al., 1994), acetylcholine (Kristt, 1983; Broide et al., 1995, 1996), and neurotrophins (Crockett et al., 2000; Vitalis et al., 2002). The latter two are of particular interest because they are important for the development of NSCs in the adult (Li et al., 2001; Hosomi et al., 2003; Cooper-Kuhn et al., 2004; Giuliani et al., 2004). They keep NSCs cycling and promote lineage definition. Potentially, such neuromodulatory systems support cycling or newly differentiating NSCs in the postnatal VB.

The present study tested the hypotheses that the trigeminal-somatosensory system uses a nonhierarchical manner of development and, in contrast to the contemporary understanding of thalamic development, that the VB experiences postnatal neuronogenesis.

\section{Materials and Methods \\ Animals}

Pregnant Long-Evans rats were obtained from Harlan Sprague Dawley (Indianapolis, IN) on G4. The day that a sperm-positive plug was first seen was defined as G1. Animals were maintained in an Association for Assessment and Accreditation of Laboratory Animal Care-approved facility at the Syracuse Veterans Affairs Medical Center (VAMC). All procedures were approved by the Institutional Animal Care and Use Committee of the VAMC and the Committee on the Humane Animal Use at Upstate Medical University.

At birth, litters were culled to 10 . Offspring were weaned on postnatal day 21 (P21). To ensure a common scale for the developmental timeline, $\mathrm{G} 22$ was designated as $\mathrm{P} 0$ regardless of the actual day of birth. One animal from each of five litters was perfused transcardially with $4.0 \%$ paraformaldehyde in $0.10 \mathrm{~m}$ phosphate buffer (PB), pH 7.4, at various times between $\mathrm{P} 0$ and P21. Each brain was removed, postfixed in buffered paraformaldehyde for $4 \mathrm{~h}$, cryoprotected, and stored in $30 \%$ sucrose in PB.

\section{Cell proliferation studies}

Prenatal neurogenesis. Four dams were given injections of $\left[{ }^{3} \mathrm{H}\right]$ thymidine $\left(\left[{ }^{3} \mathrm{H}\right] \mathrm{dT}\right)$ on each day during the period between G13 and G17 inclusive. $\left[{ }^{3} \mathrm{H}\right] \mathrm{dT}$ was used for these studies because it is ideal for use in birthdating studies wherein it is necessary to discriminate first-generation neurons from succeeding generations (Miller, 1985, 1988). An offspring from each litter was killed on P21. These animals were used to verify prenatal times of generation of VB neurons.

Postnatal neurogenesis. One animal from each of three litters was given an injection of the thymidine analog bromodeoxyuridine (BrdU; $25 \mathrm{mg} /$ $\mathrm{kg}$; Sigma, St. Louis, MO) on P6 or P21. BrdU was appropriate for these studies because it lent itself to short-term studies of cell proliferation and for fluorescence labeling studies (Miller and Nowakowski, 1988). These animals were perfused at various times $(2-6 \mathrm{~h}$ or 3 or $15 \mathrm{~d})$ after the injection. Sections were collected as described below. Immunohistochemistry was used to localize dual expression of BrdU and one of various cell type-dependent and developmental state-dependent markers (Table 1).

One animal from each of three litters that received an injection of BrdU on P6 also received an intracerebral injection of biotinylated dex$\operatorname{tran}(0.020 \mu \mathrm{l}$ of $1.0 \mathrm{mg} / 100 \mu \mathrm{l}$ saline; D1956; Invitrogen, San Diego, CA) on P24. Animals were perfused 1 week after dextran injection, and brains were processed for double immunofluorescence.

Three animals from two different litters were used to assess cell cycle kinetics. These animals received injections of BrdU $(25 \mathrm{mg} / \mathrm{kg})$ on P6. Thirty minutes later, one animal from each litter was perfused, and the brain was collected. Two hours after the first injection, the remaining four siblings received a second injection of BrdU. Once again, $30 \mathrm{~min}$ after the second injection, one animal per litter was killed and the brain was harvested. The remaining two rats received a third injection of $\mathrm{BrdU}$ $2 \mathrm{~h}$ after the second and were perfused 30 min later. Brains from all six animals were processed for BrdU immunolabeling.

\section{Tissue preparation}

Using a Leica (Nussloch, Germany) CM1900 cryostat, sets of $12-\mu \mathrm{m}$ thick sections of the forebrain were collected from each brain. The periodicity of the series varied among the different ages: at P0 and P3, every 10th section was taken; at P6, every 15 th section was taken; and at P12 and later, every 20th section was collected. One set was stained with cresyl violet for counting neurons. A second set was stained to localize acetylcholinesterase (AChE) activity for delineation of the boundaries of the developing VB. Third, fourth, fifth, and sixth sets of sections were immunolabeled for NeuN or HuC/D (markers for mature neurons), Ki-67 (a marker for cells in all phases of the cell cycle), p75 (the low-affinity neurotrophin receptor), and pan-trk (the high-affinity neurotrophin receptors). Other sets were used in the double-labeling studies (see below).

\section{AChE histochemistry}

Sections were incubated in the stain solution containing $0.50 \mathrm{mg} / \mathrm{ml}$ acetylthiocholine iodide, $0.10 \mathrm{M}$ sodium acetate, $0.10 \mathrm{M}$ acetic acid, $0.10 \mathrm{M}$ sodium citrate, $30 \mathrm{~mm}$ copper sulfate, $4.0 \mathrm{~mm}$ tetraisopropylpyrophosoamide, and $5.0 \mathrm{~mm}$ potassium ferricyanide, pH 5.5 (El-Badawi and Schenk, 1967; Mooney and Miller, 1999). This incubation was performed in the dark at $37^{\circ} \mathrm{C}$ for $3 \mathrm{~h}$. Subsequently, tissue was dehydrated through graded alcohols and cleared before coverslipping. Differential thalamic AChE staining was used to delineate the borders of the VB, specifically the medial and lateral segments of the ventral posterior nucleus (VPm and VPl, respectively) (Kristt, 1983). The VB was identified using the criteria described by Paxinos and Watson (1982).

\section{Immunohistochemistry}

Sections were immunolabeled for markers identifying stage-specific cells. Antigen retrieval was performed by heating sections in $0.01 \mathrm{M}$ citrate buffer, $\mathrm{pH}$ 6.0. Nonspecific antibody binding was quenched by a wash in PB containing $0.10 \%$ Triton X-100 (TPB), $4.0 \%$ goat serum, and $1.0 \%$ bovine serum albumin. Sections were incubated for $1 \mathrm{~h}$ with a primary antibody directed against p75, pan-trk, Ki-67, BrdU, NeuN, or HuC/D (Table 1). Unbound antibody was removed by washing in $5.0 \%$ nonfat milk in PB (mPB). Biotinylated secondary antibody (1:200; Vector Laboratories, Burlingame, $\mathrm{CA}$ ) was applied for $1 \mathrm{~h}$. Sections were rinsed in $\mathrm{mPB}$ and incubated with a Vectastain Elite kit (Vector Laboratories). Immunoreactivity was visualized by incubating the sections in $3,3^{\prime}$ diaminobenzidine (Vector Laboratories) in the presence of hydrogen peroxide. Sections were counterstained with cresyl violet. All steps were performed at room temperature. Nonspecific labeling was examined by omitting either the primary or the secondary antibody.

To determine the identity of the dividing cells, dual immunofluorescence was used to colocalize BrdU with markers for immature and ma- 
ture neural cells. Nonspecific antibody labeling was blocked by incubation in TPB containing $4.0 \%$ goat serum and $1.0 \%$ bovine serum albumin. All sections were treated with $0.0070 \mathrm{~N} \mathrm{NaOH}$ to produce single-stranded DNA and incubated in an antibody to BrdU on singlestranded DNA. The BrdU immunolabel was visualized with a secondary antibody conjugated with fluorescein. Subsequently, the sections were processed with a second primary antibody for a cell type-specific marker (Table 1) and a rhodamine-tagged secondary antibody. Sections were also labeled with bis-benzamide (1:400 in PB; Hoescht 33341, B2261; Sigma), a DNA marker, to label all nuclei and thus allow determination of a cytoarchitectonic area. For the double-labeling studies with the dextran, the dextran was conjugated with fluorescein isothiocyanate (1:200 in PB; 016-070-084; Jackson ImmunoResearch, West Grove PA) and the BrdU with a primary antibody and a secondary antibody conjugated to Texas Red strepavidin (1:200 in PB; Fl6000; Vector Laboratories). Fluorescent immunolabeling was visualized with a Zeiss (Thornwood, NY) Axioplan 2E Imaging fitted with appropriate filters and structured illumination (Zeiss Apotome) or with a Leica microscope outfitted with a confocal laser (Bio-Rad, Hercules, CA).

\section{Tritiated-thymidine autoradiography}

The brains of the offspring of rats given injections of $\left[{ }^{3} \mathrm{H}\right] \mathrm{dT}$ were removed, embedded in paraffin, and cut into a series of $10 \mu \mathrm{m}$ sections. The sections were deparaffinized, dehydrated, cleared, rehydrated, and dipped in NTB2 Nuclear Track Emulsion (Kodak, Rochester, NY). The autoradiographs were developed for 25-28 d, fixed, cleared, dehydrated, counterstained with cresyl violet, and coverslipped.

\section{Data analyses}

Labeling frequencies. The labeling frequency for VB cells expressing BrdU or Ki-67 was determined in brains collected $6 \mathrm{~h}$ after injection of BrdU on P6 or P21 using the Bioquant Image Analysis system (R\&M Biometrics, Nashville, TN). Counts were made of the total number of neurons within a square box $(100 \times 100 \mu \mathrm{m})$ and the number of cells immunopositive for BrdU or Ki-67. The labeling frequency was calculated as the number of immunopositive cells divided by the total number of neurons counted.

Autoradiographic analyses. Cells were identified as being heavily or lightly labeled depending on the relative number of grains overlying them (Miller 1985, 1988). Heavily labeled cells had greater than half the maximal number of grains over their nuclei. These cells were presumed to have been in their final mitosis when the $\left[{ }^{3} \mathrm{H}\right] \mathrm{dT}$ was injected. Lightly labeled neurons had less than half the number of grains as that over the most heavily labeled neurons and more than double background. Conservatively, background was two grains per nucleus (i.e., two grains per $50 \mu \mathrm{m}^{2}$ ). Cells were lightly labeled (1) if they underwent more than one mitotic division subsequent to the $\left[{ }^{3} \mathrm{H}\right] \mathrm{dT}$ injection or (2) the somata of a heavily labeled neuron was too deep in the section to be detected as heavily labeled (e.g., the crown of the nucleus only broached the upper 2 $\mu \mathrm{m}$ of the section, the zone that affects the overlying emulsion).

Stereological methods. The boundaries of the VB were determined in the AChE- and cresyl violet-stained sections using the Bioquant Image Analysis system. Each image was projected to a monitor, and the borders of the VB and its subnuclei (VPm and VPl) were traced. Cavalieri's estimator of volume was used to calculate the volume $\left(V_{\mathrm{T}}\right)$ by the following formula:

$$
V_{\mathrm{T}}=\Sigma a_{\mathrm{i}} \times s_{\mathrm{f}}
$$

where $a_{\mathrm{i}}$ is the cross-sectional area of the thalamic nucleus on the $i$ th profile and $s_{\mathrm{f}}$ is the mean distance between sections (section thickness multiplied by the inverse of the periodicity of sections in the series).

A corrected number of neurons $\left(N_{\text {corr }}\right)$ was estimated using Smolen's correction to Floderus's formula (Smolen et al., 1983; Miller and Muller, 1989; Mooney and Miller, 1999). The formula was as follows:

$$
N_{\text {corr }}=(n \times t) /(t+\bar{D}-2 k)
$$

where $n$ is the number of neurons counted in sampled areas (the counting boxes), $t$ is the section thickness, $\bar{D}$ is the mean maximal diameter, and $k$ is the diameter of the smallest recognizable cap of a cut nucleus.
The density of neurons ( $N_{\mathrm{V}}$; also called a cell packing density) was determined from the following formula:

$$
N_{\mathrm{V}}=N_{\text {corr }} /\left(\#_{\text {boxes }} \times V_{\text {box }}\right),
$$

where $V_{\text {box }}$ is the volume of one counting box (area of counting frame by section thickness).

The estimated total number of neurons in the VB, VPm, or VPl $\left(N_{\mathrm{T}}\right)$ was calculated as the product of the total volume of the VB (or a subnucleus) and the cell packing density:

$$
N_{\mathrm{T}}=N_{\mathrm{V}} \times V_{\mathrm{T}}
$$

Cell cycle kinetics. The total length of the cell cycle $\left(T_{\mathrm{C}}\right)$ was determined using a cumulative BrdU labeling technique (Nowakowski et al., 1989; Siegenthaler and Miller, 2005). BrdU incorporates into DNA of cells passing through the $\mathrm{S}$ phase, and over time, all cycling cells take up the label. The timing of the incorporation (i.e., the temporal change in the number of cells that take up BrdU) depends on the cell cycle kinetics. The data for the numbers of cells that incorporated the BrdU shortly after one, two, or three injections of BrdU were used to calculate the $T_{\mathrm{C}}$. Counts did not endeavor to differentiate among cell types (e.g., NSCs, neurons, or glia); however, endothelial cells were eliminated from the tallies. The labeling index (LI) was determined for BrdU-immunolabeled sections from animals treated with multiple BrdU injections. The total number of cells and the number of BrdU-positive cells in a $100 \times 100 \mu \mathrm{m}$ counting box were counted. The LI was calculated as the number of BrdU-immunolabeled cells divided by the sum of the numbers of labeled and unlabeled cells.

Conventionally, the proportion of cells that are actively cycling, the $\mathrm{GF}$, is determined by the cumulative labeling method that relies on the saturation of the cycling population with BrdU via a series of periodic injections (Nowakowski et al., 1989). To use fewer animals and to examine the change in the growth fraction (GF) over time, in the present study the GF was determined using Ki-67 labeling. Empirical data show that the number of cells expressing Ki-67 is the same as the number of cells that are cumulative labeled with BrdU (Siegenthaler and Miller, 2005). Accordingly, the LI for Ki-67 was determined at four ages: P6, P12, P15, and P21.

Statistical analyses. Only one rat per litter was used in generating any particular datum. The means (SEMs) were calculated for $V_{\mathrm{T}}, N_{\mathrm{v}}, N_{\mathrm{T}}, T_{\mathrm{C}}$, and GF and for the proportion of neurons generated on a particular gestational day. A one-way ANOVA was used to examine the effect of age. In situations of statistical significance, specific post hoc comparisons were performed using $t$ tests.

\section{Results}

\section{Appearance of the developing VB}

The VB was discernible in cresyl violet-stained sections of the preweanling brains (Fig. 1). Throughout the early postnatal period, the VB was nestled in the crook of the internal capsule and the zona incerta. During the first postnatal week, the two subnuclei, the VPm and VPl, were difficult to distinguish in the cresyl violet; however, by the second postnatal week, the two subnuclei had distinctive appearances. The neuronal packing density was not significantly different between the subnuclei; however, between P6 and P21, the cross-sectional area of profiles of both the nuclei and somata of neurons in the VPm was $\sim 30 \%$ greater than those of neurons in the VPl.

The pattern of AChE staining changed over time. In the neonate, the VB was richly AChE positive. In fact, at this time, the VB was more intensely stained than any of the adjacent thalamic nuclei. Moreover, as early as P0, the VPl was darker that the VPm. This differential was detectable during the first postnatal week. By age P12, the VPm had noticeably lost its staining intensity, and by P21, the staining pattern was characteristic of the mature VB (i.e., both subnuclei were paler than surrounding thalamic nuclei) (cf. Kristt, 1983; Mooney and Miller, 1999). 
The temporal change in the distribution of p75 immunolabeling was similar to that of AChE activity (Fig. 1). In the neonate, p75 was richly expressed in the VPm. Staining intensity decreased with age, and by P21 there was no detectable p75 immunoreactivity in the VB. This spatiotemporal pattern of staining agrees with that described previously (Crockett et al., 2000). In contrast to the pattern of AChE staining, p75 immunoreactivity in the young pup was rich in the VPm and virtually absent in the VPl. Labeling with the pan-trk antibody, which labels all three highaffinity neurotrophin receptors (trkA, $\operatorname{trkB}$, and trkC), showed the same spatiotemporal pattern as seen with p75. Trk expression was high in the young animal and attenuated by the third postnatal week (data not shown).

\section{$\left[{ }^{3} \mathrm{H}\right] \mathrm{dT}$ labeling of prenatally generated neurons}

Neurons in the two subnuclei of the VB were heavily labeled by injections of $\left[{ }^{3} \mathrm{H}\right] \mathrm{dT}$ on either G14 or G15 (Fig. 2). Heavily labeled neurons were seen in both the VPm and VPl after $\left[{ }^{3} \mathrm{H}\right] \mathrm{dT}$ injection on G14 or G15. Similar numbers of neurons were born on each day. No heavily labeled neurons were evident in the VB after an injection on G13, G16, or G17 (data not shown).

\section{Numbers of neurons in the VB}

The total number of neurons in the VB was calculated as the product of the volume of the VB and the mean cell packing density. The total volume of the VB increased 10fold during the first postnatal month $\left(F_{(5,20)}=80.427 ; p<0.001\right)$ (Fig. 3). The volume of each subnucleus also increased over this time. Moreover, during the first three postnatal weeks, the VPm was consistently (1.41- to 1.72 -fold) and significantly $(p<0.05)$ larger than the VPl.

Concomitant with the increase in the VB volume, there was a progressive decrease in the neuronal packing density with age $\left(F_{(5,20)}=147.22 ; p<0.001\right)$. The biggest decrease occurred during the first postnatal week, and the density evident on P12 was not significantly different from that in 21 - and 30 -d-old rats. No differences between the neuronal packing density in the VPm and VPl were detected at any age examined.

The number of neurons in the VB was determined by calculating the product of the volume and neuronal packing density. Accordingly, there was a significant effect of age $\left(F_{(3,12)}=12.410\right.$; $p<0.001)$ on the total number of neurons in the VB. Post hoc analyses showed that the total number of neurons significantly $(p<0.001)$ fell between P0 and P3. Surprisingly, the number of neurons increased significantly $(p<0.001)$ between P3 and P12 and then again between P12 and P21. The number of neurons fell significantly $(p<0.05)$ between P21 and P30 [the latter data were described in a previous study (Mooney and Miller, 1999)].

To verify that only neurons were included in the analyses of the cresyl violet-stained sections, sections immunolabeled with an anti-NeuN antibody were examined. The numbers of VB cells that were NeuN positive on P12 and on P21 were not significantly different from numbers determined using sections stained with cresyl violet.

The change in the number of neurons in the two subnuclei was determined. As with the overall numbers of VB neurons, the numbers of neurons in the VPm and VPl rose during the first three postnatal weeks. Furthermore, over the times examined, the VPm comprised 1.61-fold more neurons than the VPl.

\section{Postnatal generation of neurons in the VB \\ BrdU labeling}

To address the possibility that neuronal generation occurred in the VB during the postnatal period, animals received injections of BrdU on P6 or P21. Six hours after injecting the BrdU, $12.5 \%$ of cells in the VB were labeled by an injection on P6 (Fig. 4). In contrast, only $1.5 \%$ of $\mathrm{VB}$ cells incorporated BrdU that was administered on P21. Animals given injections on P6 exhibited BrdU-positive cells in the VB as early as 30 min after injection, indicating that the cell proliferation occurred within the VB and that the cells did not migrate from the ventricular zone (VZ) of the third ventricle. 


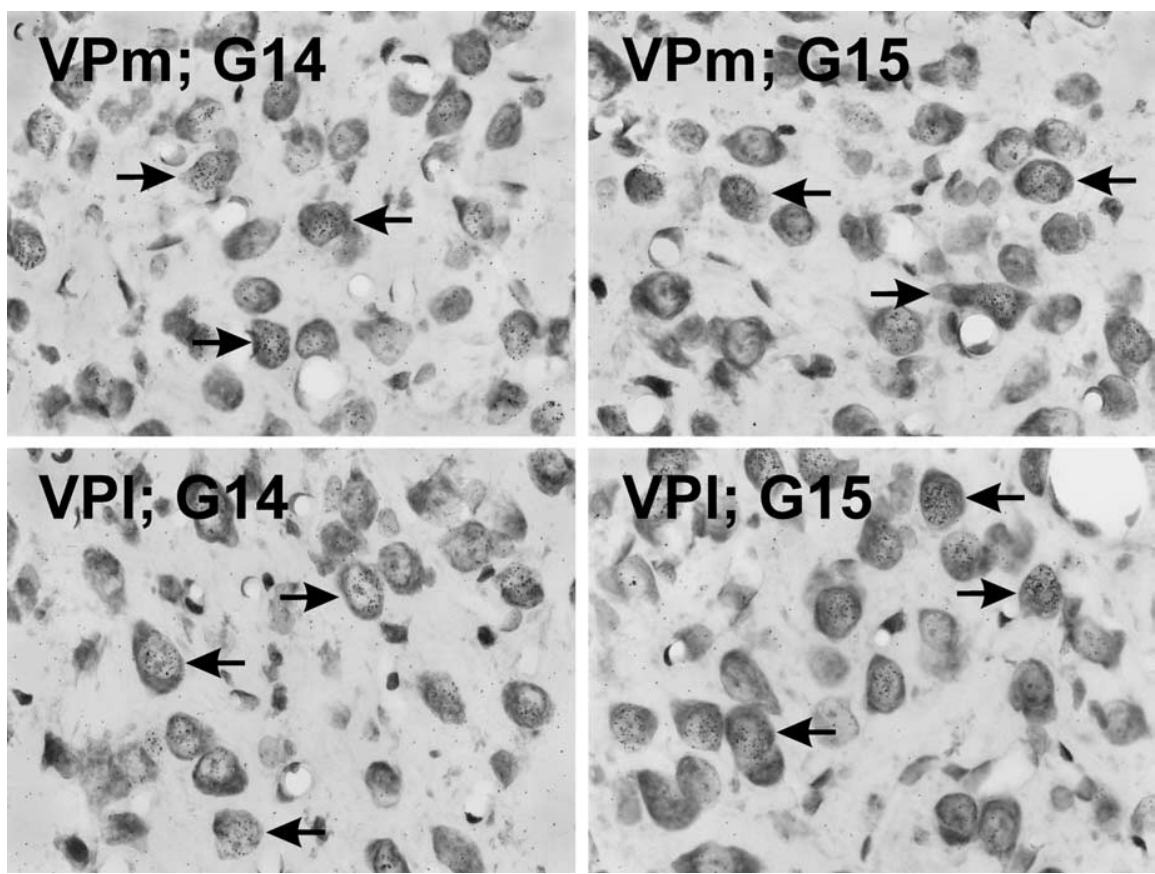

Figure 2. Prenatal neuronogenesis. Mature offspring of pregnant dams that received injections of [ $\left.{ }^{3} \mathrm{H}\right] \mathrm{dT}$ on $\mathrm{G} 14$ (left) or G15 (right) had many heavily labeled neurons (arrows) in the VB. Top, VPm; bottom, VPI. Scale bars, $50 \mu \mathrm{m}$.

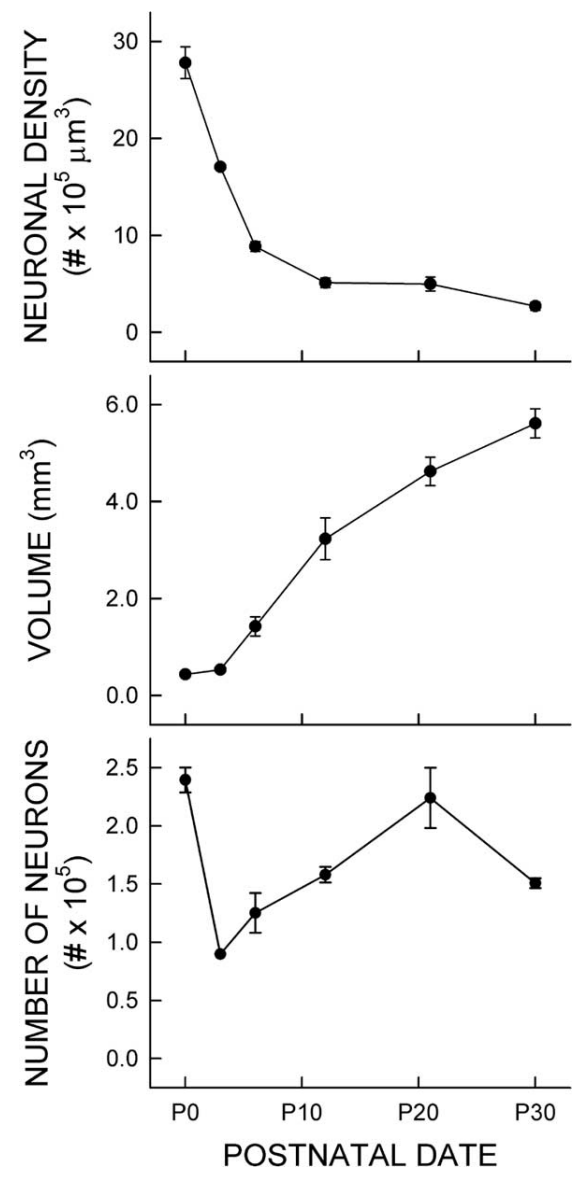

Figure 3. Morphometry of the VB. Three parameters pertaining to the development of the VB were quantified. Top, The neuronal packing density was determined stereologically. Middle, Cavalieri's estimator of volume was used to determine the total volume of the VB. Bottom, The product of these values was the total number of neurons. Means are based on five animals per time point. Error bars indicate SEM.

\section{Cell cycle kinetics}

The combination of cumulative BrdU and Ki-67 labeling allowed for determination of the cell cycle kinetics (Fig. 5). During the $6.5 \mathrm{~h}$ after the first injection of BrdU, the number of BrdU-positive cells increased. By fitting these data to a linear regression $(r=0.9936 ; p=0.0064)$, the $T_{\mathrm{C}}$ was estimated to be $17.3 \pm 0.9 \mathrm{~h}$. This was similar to that determined for cells in the cortical VZ on G21 (Miller and Nowakowski, 1991). The LI for Ki-67 (i.e., the GF) was stable between P6 and P12. The mean GF was $27.4 \pm 0.9 \%$. By P21, the LI dropped significantly $(p<0.01)$ to $7.7 \%$, indicating a reduction in the proliferative population.

\section{Identity of proliferating cells}

To determine the identity/fate of BrdUpositive cells, brains were examined 2,6 , or $15 \mathrm{~d}$ after injection (i.e., on P8, P12, or $\mathrm{P} 21)$. On P8, BrdU mostly colocalized with markers for NSCs (vimentin or nestin) or immature neurons (Tuj1) (Fig. 6). By P12, BrdU colocalized with mature neuronspecific markers NeuN, HuC/D (Fig. 7 and supplemental Figs. 1, 2, available at www. jneurosci.org as supplemental material), or MAP2 (microtubuleassociated protein 2; data not shown). It is noteworthy that the $\mathrm{NeuN}$ and $\mathrm{HuC} / \mathrm{D}$ immunostaining were expressed in the nuclei and perikarya (Mullen et al., 1992; Wolf et al., 1996). (n.b. The balance of nuclear/perikaryal NeuN immunolabeling was tipped by the $\mathrm{pH}$ of the antigen-retrieval buffer.) Double labeling was also evident in pups receiving injections of BrdU on P6 and with a biotinylated dextran placed in somatosensory cortex on P24 (Fig. 6 and supplemental Fig. 3, available at www.jneurosci.org as supplemental material). The VB of these animals exhibited a subset of BrdU-positive cells that were also dextran positive. This indicated that the neurons generated postnatally (1) projected to the cortex and (2) these projection neurons survived for at least 3 weeks. Some cells exhibited BrdU and GFAP immunolabeling or BrdU and Iba1 immunolabeling.

Cerebral cortex and hippocampus were examined for comparative purposes. BrdU-positive cells in neocortex did not coexpress NeuN, but BrdU-positive/GFAP-positive cells were common (supplemental Fig. 4, available at www.jneurosci.org as supplemental material). The implication is that early postnatal neurogenesis in cortex leads to the production of glia and not neurons. In contrast, double NeuN-BrdU labeling was evident in the hippocampal formation.

\section{Lateral geniculate nucleus}

It is noteworthy that the $\mathrm{VB}$ was not unique among thalamic nuclei insofar as its cytoarchitectural and chemoarchitectural development. For example, the lateral geniculate nucleus (LGN) followed a parallel developmental course to that described for the VB. The spatiotemporal pattern of both AChE activity and p75 immunoreactivity in the dorsal and ventral LGN was identical to that for the VPm and VPl, respectively (Fig. 1). Moreover, BrdUand Ki-67-positive cells were common in the LGN throughout the period from P3 to P21 (data not shown). Double labeling with 
BrdU and a neuronal marker was also identified in the LGN $6 \mathrm{~d}$ after the BrdU was administered on P6 (data not shown).

\section{Discussion}

\section{Periods of VB neuronogenesis}

VB neurons are generated during two periods. The first period occurs prenatally, on G14 and G15 (Altman and Bayer, 1989). The second period occurs during the preweaning period, between P3 and $\mathrm{P} 21$. Over this time, neuronal number increases 2.5-fold.

That VB neurons are generated postnatally is supported by two independent sets of data: (1) stereological determination of total neuronal number traces a longitudinal increase in the number of neurons during the second and third postnatal weeks; and (2) VB neurons incorporate BrdU administered postnatally. It is important to note that the BrdU is incorporated into cycling cells (as opposed to cells repairing their DNA) as evidenced by colabeling of BrdU with nestin and Ki-67 (Gerdes et al., 1983, 1984; Scholzen and Gerdes, 2000; Siegenthaler and Miller, 2005).

Discovering a second period of neuronogenesis is surprising. Although dividing cells in the postnatal VB have been demonstrated (Altman and Das, 1966), the identity of these cells has remained unknown and presumed to be glia. The present study shows that many cells cycling in the postnatal VB become neurons. Indeed, colocalization of a dextran transported retrogradely from neocortex with BrdU in thalamic neurons shows that postnatally generated thalamic neurons not only survive but they integrate into the system.

\section{Source of postnatal neuronogenesis}

In contrast to the prenatal generation of $\mathrm{VB}$ neurons that occurs in the diencephalic VZ, postnatal neuronogenesis occurs in the VB per se. Evidence of BrdU-positive cells in the VB 30 min after injection shows that cells divide in situ rather than being generated elsewhere (e.g., the VZ) and migrating into the VB. After all, the cells that incorporate the BrdU are in S phase, and they must complete the cycle (i.e., pass through $\mathrm{G}_{2}, \mathrm{M}$, and the beginning of $\mathrm{G}_{1}$ ) before they can migrate. Furthermore, radial migration of prosencephalic neurons in the rat occurs at a rate of 5-6 $\mu \mathrm{m}$ per hour (Miller, 1999; Siegenthaler and Miller, 2004), and if the cells are born in the diencephalic VZ, they must travel a distance of 600 $\mu \mathrm{m}$ or more. Neither the passage of cells through the remaining cell cycle nor their migration can be accomplished in $30 \mathrm{~min}$, much less the sum of both processes. Therefore, the postnatally generated neurons must have originated in the VB.

Using the cell cycle kinetic data (Fig. 5) and the change in cell number (Fig. 3), the number of cells produced daily can be estimated. Based on a mathematical model (Miller, 2003), it is estimated that 51,300 cells (i.e., neurons and glia) per day are produced in the VB. Even allowing for gliogenesis and the death of a fraction of these cells, this production more than explains the documented addition of 7500 neurons per day.

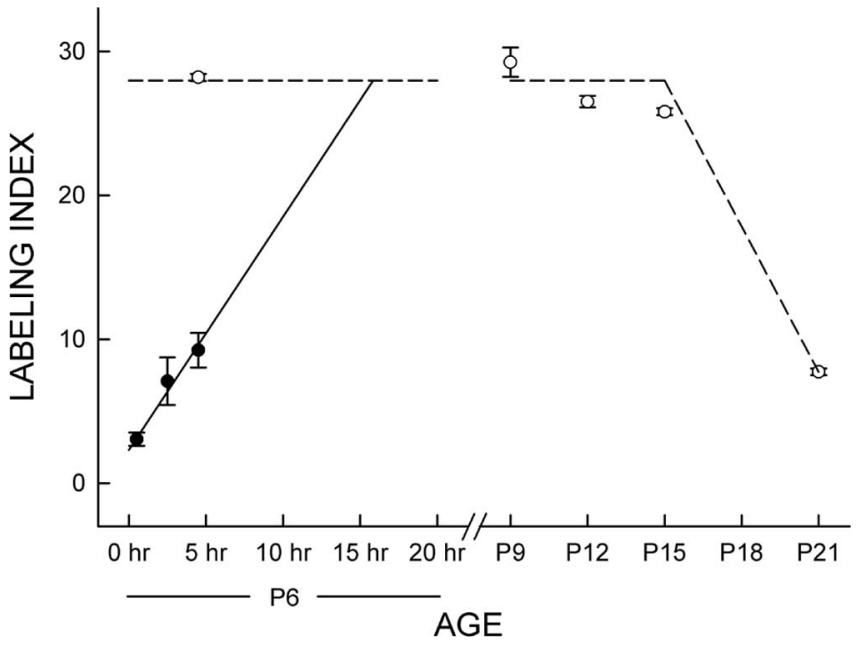

Figure 5. Cell cycle kinetics for postnatal proliferation in the VB. BrdU incorporation among cycling cells increases after a series of injections on P6 (solid symbols and line). This is evident by an increase in the mean LI(SEMs). A regression line was fitted to the primary data, the slope $(m)$ of which was the dividend of the GF and the total length of the cell cycle $\left(T_{C}\right): m=G F / T_{C}$. The GF was determined as the percentage of cells that was Ki-67 immunoreactive (open circles and dashed lines). This $\mathrm{LI}$ was measured at five times: $\mathrm{P} 6, \mathrm{P} 9, \mathrm{P} 12, \mathrm{P} 15$, and $\mathrm{P} 21$. It remained at a steady amount until the end of the third postnatal week when it fell significantly $(p<0.01)$.

\section{Postnatal neuronal generation beyond the VB}

Postnatal neural generation is not confined to the VB. BrdU- and Ki-67-positive cells are present in other structures, notably the hippocampus, olfactory system, neocortex, and lateral geniculate nuclei. In essence, the hippocampal formation serves as a positive control, and the neocortex serves as a negative control.

Postnatal neuronogenesis occurs in nonthalamic parts of the CNS. Granule neurons of the dentate gyrus are generated in the subgranular (intrahilar) zone in the early postnatal period and 

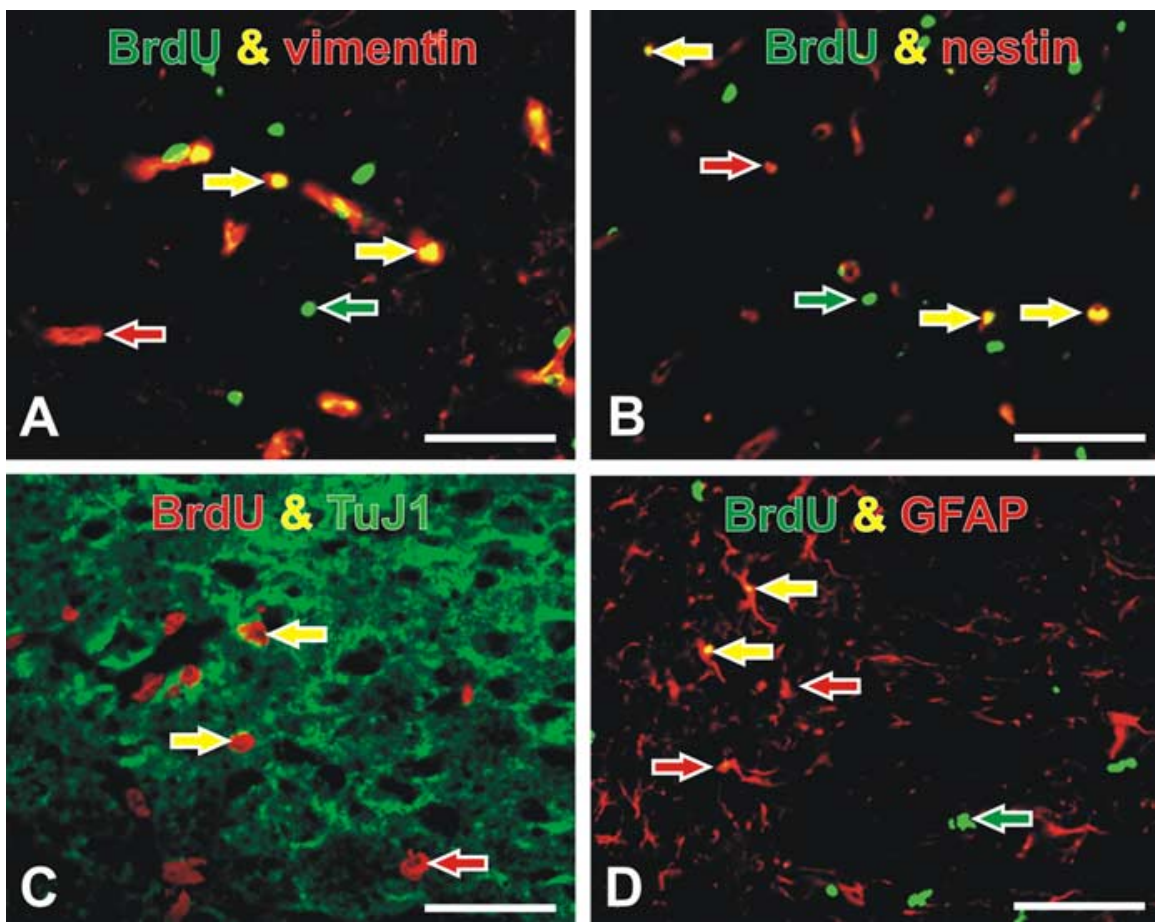

Figure 6. Phenotype of immature cells. Animals were given injections of BrdU on P6 and killed on P8. A, B, Cells that were singly labeled with BrdU or vimentin/nestin are indicated by red and green arrows, respectively. Some BrdU-labeled cells were vimentin or nestin positive (yellow arrows). C, A subset of BrdU-positive cells were TuJ1 positive (yellow arrows). D. Some BrdU-positive cells expressed the glia-specific marker GFAP (yellow arrows). Scale bars, $50 \mu \mathrm{m}$.

throughout life (Schlessinger et al., 1975, 1978; Miller 1995; Kempermann et al., 1996; Kornack and Rakic, 1999). These neurons are generated in the region proximal to the granule cell layer, but they must migrate to the positions that they ultimately occupy.

There is consensus that new olfactory bulb neurons are generated postnatally (Hinds and McNelly, 1977, 1981; Luskin, 1998; Kornack and Rakic, 2001a). These neurons are generated in a site of origin (the anterior subventricular zone) distant from their eventual residence, and the young neurons must traverse a great distance via the rostral migratory stream to get to the bulb.

Neurogenesis occurs in neocortex postnatally. It is agreed that glia are generated (Levison, 2006). Although controversial, it has also been argued that neocortical neurons are also produced postnatally. Some studies show that adult cortical cells incorporate a DNA precursor $\left(\left[{ }^{3} \mathrm{H}\right] \mathrm{dT}\right.$ or BrdU) and that the ultrastructure (Kaplan and Hinds, 1977, 1980) or protein profile (Gould et al., 2001) indicate that some of these cells become neurons. This situation is further complicated because some evidence shows that cortical neuronogenesis occurs in situ (Kaplan and Hinds, 1977,1980 ), whereas other data show that these new neurons are born in the neocortical proliferative zones and migrate to neocortex (Gould et al., 2001). Others disagree with the interpretation of these data arguing that incorporation of $\left[{ }^{3} \mathrm{H}\right] \mathrm{dT}$ or BrdU is evidence of DNA synthesis that is not associated with cell division (Kornak and Rakic, 2001b; Rakic, 2002). In the case of the $\mathrm{VB}$, this criticism is addressed by finding BrdU and Ki-67 colabeling in VB cells.

\section{Factors influencing postnatal neuronogenesis}

Perhaps the most interesting question to ponder is why the number of neurons drops neonatally and then rises again. The initial drop concurs with the transient appearance of pyknotic cells (Waite et al., 1992; Mai et al., 1998) and a change in the balance between expression of the anti-apoptotic bcl-2 and the pro-apoptotic bax (Mooney and Miller, 2000). Therefore, this drop can be attributed to naturally occurring neuronal death (NOND). This death is consistent with a hierarchical sequence in that it follows the death occurring in the PSN (Ashwell and Waite, 1991; Miller and AlGhoul, 1993; Miller, 1999) and precedes the NOND in the cortex (Finlay and Slattery, 1983; Ferrer et al., 1990; Miller, 1995; Miller and Kuhn, 1997).

Immature neurons compete for trophic substances that are in limited supply; some fail to find sufficient support and die (Oppenheim, 1991). For VB cells, trophic substances likely come from somatosensory cortex. Survival of neonatal thalamic neurons in vitro is enhanced by cortically conditioned medium (Lotto et al., 1997; Asavaritikrai et al., 2003). One vital trophic substance in CNS-conditioned medium responsible for the maintenance of thalamic neurons is brain-derived neurotrophic factor (BDNF). Four independent sets of data imply that transported cortexderived BDNF plays a role in the survival of VB neurons: (1) BDNF mRNA is undetectable in the VB between G15.5 and P15, and $\mathrm{VB}$ neurons are $\mathrm{BDNF}$ responsive (Baquet et al., 2004); (2) the thalamus of the preweanling expresses p75 and trk during the period of postnatal neuronogenesis, and this expression wanes by $\mathrm{P} 21$ when this production is virtually complete; (3) inactivation of trkB, the high-affinity receptor for BDNF, results in increased cell death in VB (Vitalis et al., 2002); and (4) conversely, injection of BDNF into cortex on P2 enhances the survival of thalamic neurons (Lotto et al., 2001).

As discussed above, the rise in the number of VB neurons during the second and third postnatal weeks results from postnatal neuronogenesis. Growth factors such as BDNF appear to be involved in this generation. Infusion of BDNF into the lateral ventricle of adult rats induces cell generation in numerous brain areas including thalamus (Pencea et al., 2001). This is consistent with evidence of a population of BDNF-responsive quiescent stem cells in mature thalamus. Conceivably, the transiently high expression of BDNF in cortex in the second and third postnatal weeks (Climent et al., 2002) triggers the second wave of proliferation seen in the postnatal VB. It is unclear whether the BDNF is transported through corticothalamic or thalamocortical pathways or both, although the data cited above strongly implicate corticothalamic projections. After all, neurotrophins can act through anterograde (Pitts and Miller, 1995, 2000; Wahle et al., 2003) and retrograde (DiStefano et al., 1992; Crockett et al., 2000; Wahle et al., 2003) mechanisms. The end of the second wave of neuronogenesis is punctuated by the loss of the neurotrophin receptors, both p75 and trk, during the third postnatal week.

Neurotrophins are not the only important molecules regulating VB development. For example, interactions between the VB and somatosensory cortex depend on transient serotonin transporter and AChE-expressing systems (Bennett-Clarke et al., 1991, 1996; Schlaggar et al., 1993; Schlaggar and O'Leary, 1994). The spatiotemporal change in the pattern of AChE activity (in the $\mathrm{VPl}$ ) dovetails with the changes in the neurotrophin system (in 
the VPm). Thus, whereas BDNF may be important for the VPm, other systems (e.g., serotonin transporter systems, AChE-expressing systems, other growth factors) may be key for the VPl.

The second wave of neuronal generation is nonhierarchical, at least in the sense of development following an ascending sequence (periphery $\rightarrow$ brainstem $\rightarrow$ thalamus $\rightarrow$ cortex). On the other hand, this generation coincides with the establishment of the descending corticothalamic projection (Jones, 1997; Uziel et al., 2006). This notion is supported by evidence that (1) layer VI, the source of most corticothalamic projections, has a considerable number of neurotrophin-expressing neurons (Pitts and Miller, 1995, 2000) and (2) the thalamus does not have neurons capable of manufacturing a neurotrophin(s) (Baquet et al., 2004), but it does have cells that express neurotrophin receptors (Vitalis et al., 2002; present study). Thus, cortex apparently plays a major role in establishing thalamic structure via a nonhierarchical mechanism.

\section{References}

Altman J, Bayer SA (1980) Development of the brain stem in the rat. IV. Thymidineradiographic study of the time of origin of neurons in the pontine region. J Comp Neurol 194:905-929.

Altman J, Bayer SA (1989) Development of the rat thalamus: IV. The intermediate lobule of the thalamic neuroepithelium, and the time and site of origin and settling pattern of neurons of the ventral nuclear complex. J Comp Neurol 284:534-566.

Altman J, Das GD (1966) Autoradiographic and histological studies of postnatal neurogenesis. I. A longitudinal investigation of the kinetics, migration and transformation of cells incorporating tritiated thymidine in neonate rats, with special reference to postnatal neurogenesis in some brain regions. J Comp Neurol 126:337-389.

Asavaritikrai P, Lotto B, Anderson G, Price DJ (2003) Regulation of cell survival in the developing thalamus: an in vitro analysis. Exp Neurol 181:39-46.

Ashwell KW, Waite PM (1991) Cell death in the developing trigeminal nuclear complex of the rat. Dev Brain Res 63:291-295.

Baquet ZC, Gorski JA, Jones KR (2004) Early striatal dendrite deficits followed by neuron loss with advanced age in the absence of anterograde cortical brain-derived neurotrophic factor. J Neurosci 24:4250-4258.

Bennett-Clarke CA, Chiaia NL, Crissman RS, Rhoades RW (1991) The source of the transient serotoninergic input to the developing visual and somatosensory cortices in rat. Neuroscience 43:163-183.

Bennett-Clarke CA, Chiaia NL, Rhoades RW (1996) Thalamocortical afferents in rat transiently express high-affinity serotonin uptake sites. Brain Res 733:301-306.

Broide RS, O'Connor LT, Smith MA, Smith JA, Leslie FM (1995) Developmental expression of $\alpha 7$ neuronal nicotinic receptor messenger RNA in rat sensory cortex and thalamus. Neuroscience 67:83-94.

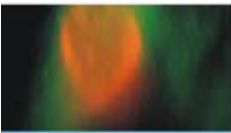
$\mu \mathrm{m} ; \mathbf{D}-\boldsymbol{K}, 10 \mu \mathrm{m}$.
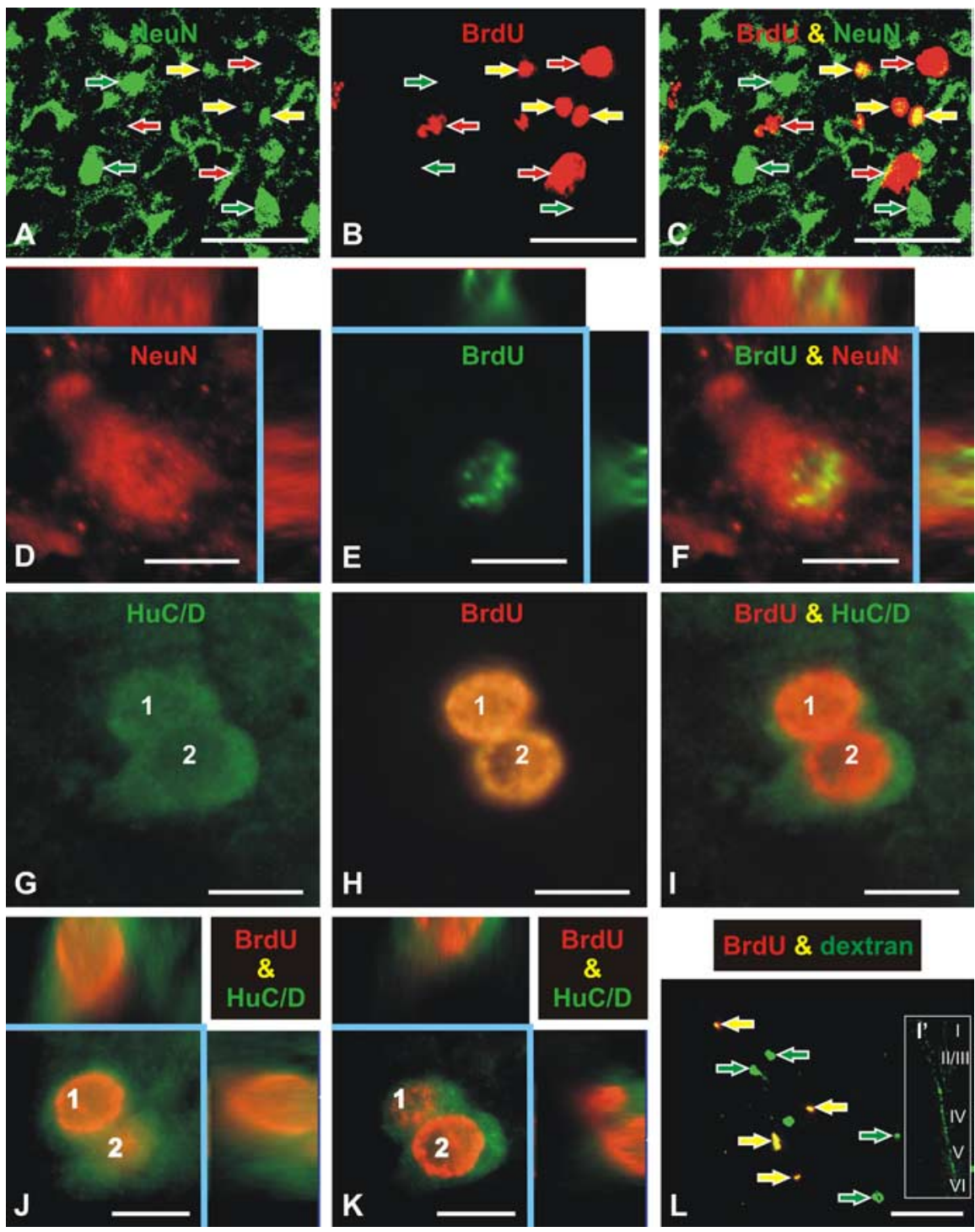

BrdU \& dextran

Figure 7. Phenotype of cycling cells. Double immunofluorescent labeling studies were used to determine that some of the cycling cells (labeled by an injection of BrdU on P6) expressed neuron-specific markers $\geq 6 \mathrm{~d}$ after injection. $\boldsymbol{A}-\boldsymbol{C}$, Confocal images were obtained with optical section thickness of $1.0 \mu \mathrm{m}$. Sections processed for NeuN ( $\boldsymbol{A}$; green arrows) and BrdU ( $\boldsymbol{B}$; red arrows) immunohistochemistry are shown. Many BrdU-positive cells were NeuN positive ( $\boldsymbol{C}$; yellow arrows). $\boldsymbol{D}-\boldsymbol{F}$, Images of double labeling with anti-NeuN $(\boldsymbol{D})$ and anti-BrdU $(\boldsymbol{E})$ antibodies. $\boldsymbol{F}$ shows colocalization of the labels in a merged image flanked by images at orthogonal planes through the cell. The orthogonal images were compiled from stacks of $1.0 \mu \mathrm{m}$ optical images. $\mathbf{G}-\boldsymbol{K}$, Images of labeling with anti-HuC/D antibody $(\boldsymbol{G})$ and anti-BrdU antibody $(\boldsymbol{H})$. The merged images show colocalization of the labels. I,J, Az-series of images was taken through the section shown in $\mathbf{G}$. Individual images were taken at planes that highlighted a nuclear profile of cell $1(I)$ and cell $2(J)$. Orthogonal views show that for each cell, both antigens were coexpressed. Images for each antibody reaction are shown in supplemental Figure 2 (available at www.jneurosci.org as supplemental material). L, Animals given injections of BrdU on P6 were given an intracerebral injection of biotinylated dextran on P24 (box inset, $I^{\prime}$ ). One week later (on P31), cells in the VB that colocalized BrdU and dextran were identified (yellow arrows). Images representing the individual channels are shown in supplemental Figure 3 (available at www.jneurosci.org as supplemental material). Scale bars: $A-C, L, 50$

Broide RS, Robertson RT, Leslie FM (1996) Regulation of $\alpha 7$ nicotinic acetylcholine receptors in the developing rat somatosensory cortex by thalamocortical afferents. J Neurosci 16:2956-2971.

Bruning G, Liangos O (1997) Transient expression of the serotonin transporter in the developing mouse thalamocortical system. Acta Histochem 99:117-121.

Climent E, Pascual M, Renau-Piqueras J, Guerri C (2002) Ethanol exposure enhances cell death in the developing cerebral cortex: role of brainderived neurotrophic factor and its signaling pathways. J Neurosci Res 68:213-225.

Cooper-Kuhn CM, Winkler J, Kuhn HG (2004) Decreased neurogenesis 
after cholinergic forebrain lesion in the adult rat. J Neurosci Res 77:155-165.

Crockett DP, Harris SL, Egger MD (2000) Neurotrophin receptor (p75) in the trigeminal thalamus of the rat: development, response to injury, transient vibrissa-related patterning, and retrograde transport. Anat Rec 259:446-460.

DiStefano PS, Friedman B, Radziejewski C, Alexander C, Boland P, Schick CM, Lindsay RM, Wiegand SJ (1992) The neurotrophins BDNF, NT-3, and NGF display distinct patterns of retrograde axonal transport in peripheral and central neurons. Neuron 8:983-993.

El-Badawi A, Schenk EA (1967) Histochemical methods for separate, consecutive and simultaneous demonstration of acetylcholinesterase and norepinephrine in cryostat sections. J Histochem Cytochem 15:580-588.

Ferrer I, Bernet E, Soriano E, del Rio T, Fonseca M (1990) Naturally occurring cell death in the cerebral cortex of the rat and removal of dead cells by transitory phagocytes. Neuroscience 39:451-458.

Finlay BL, Slattery M (1983) Local differences in the amount of early cell death in neocortex predict adult local specializations. Science 219:1349-1351.

Fitzgibbon T (2006) Does the development of the perigeniculate nucleus support the notion of a hierarchical progression within the visual pathway? Neuroscience 140:529-546.

Fujimiya M, Kimura H, Maeda T (1986) Postnatal development of serotonin nerve fibers in the somatosensory cortex of mice studied by immunohistochemistry. J Comp Neurol 246:191-201.

Gerdes J, Schwab U, Lemke H, Stein H (1983) Production of a mouse monoclonal antibody reactive with a human nuclear antigen associated with cell proliferation. Int J Cancer 31:13-20.

Gerdes J, Lemke H, Baisch H, Wacker HH, Schwab U, Stein H (1984) Cell cycle analysis of a cell proliferation-associated human nuclear antigen defined by the monoclonal antibody Ki-67. J Immunol 133:1710-1715.

Giuliani A, D'Intino G, Paradisi M, Giardino L, Calza L (2004) p75(NTR)immunoreactivity in the subventricular zone of adult male rats: expression by cycling cells. J Mol Histol 35:749-758.

Gould E, Vail N, Wagers M, Gross CG (2001) Adult-generated hippocampal and neocortical neurons in macaques have a transient existence. Proc Natl Acad Sci USA 98:10910-10917.

Hinds JW, McNelly NA (1977) Aging of the rat olfactory bulb: growth and atrophy of constituent layers and changes in size and number of mitral cells. J Comp Neurol 72:345-367.

Hinds JW, McNelly NA (1981) Aging in the rat olfactory system: correlation of changes in the olfactory epithelium and olfactory bulb. J Comp Neurol 203:441-453.

Hosomi S, Yamashita T, Aoki M, Tohyama M (2003) The p75 receptor is required for BDNF-induced differentiation of neural precursor cells. Biochem Biophys Res Commun 301:1011-1015.

Jones EG (1997) Cortical development and thalamic pathology in schizophrenia. Schizophrenia Bull 23:483-501.

Kaplan MS, Hinds JW (1977) Neurogenesis in the adult rat: electron microscopic analysis of light radiographs. Science 197:1092-1094.

Kaplan MS, Hinds JW (1980) Gliogenesis of astrocytes and oligodendrocytes in the neocortical grey and white matter of the adult rat: electron microscopic analysis of light radioautographs. J Comp Neurol 193:711-727.

Kempermann G, Kuhn HG, Gage FH (1996) Genetic influence on neurogenesis in the dentate gyrus of adult mice. Proc Natl Acad Sci USA 9:19409-19414

Kornack DR, Rakic P (1999) Continuation of neurogenesis in the hippocampus of the adult macaque monkey. Proc Natl Acad Sci USA 96:5768-5773.

Kornack DR, Rakic P (2001a) The generation, migration, and differentiation of olfactory neurons in the adult primate brain. Proc Natl Acad Sci USA 98:4752-4757.

Kornack DR, Rakic P (2001b) Cell proliferation without neurogenesis in adult primate neocortex. Science 294:2127-2130.

Kristt DA (1983) Acetylcholinesterase in the ventrobasal thalamus: transience and patterning during ontogenesis. Neuroscience 10:923-939.

Levison S (2006) Mammalian subventricular zones: their roles in brain development, cell replacement and disease. New York: Springer.

Li BS, Ma W, Zhang L, Barker JL, Stenger DA, Pant HC (2001) Activation of phosphatidylinositol-3 kinase (PI-3K) and extracellular regulated kinases
(Erk1/2) is involved in muscarinic receptor-mediated DNA synthesis in neural progenitor cells. J Neurosci 21:1569-1579.

Lotto RB, Clausen JA, Price DJ (1997) A role for neurotrophins in the survival of murine embryonic thalamic neurons. Eur J Neurosci 9:1940-1949.

Lotto RB, Asavaritikrai P, Vali L, Price DJ (2001) Target-derived neurotrophic factors regulate the death of developing forebrain neurons after a change in their trophic requirements. J Neurosci 21:3904-3910.

Luskin MB (1998) Neuroblasts of the postnatal mammalian forebrain: their phenotype and fate. J Neurobiol 36:221-233.

Mai JK, Ashwell KW, Waite PM, Krajewski S, Reed JC (1998) Bcl-x and Bcl-2 immunoreactivity in postnatal mouse barrel fields. NeuroReport 9:4155-4159.

Miller MW (1985) Co-generation of projection and local circuit neurons in neocortex. Dev Brain Res 23:187-192.

Miller MW (1988) Effect of prenatal exposure to ethanol on the development of cerebral cortex: I. Neuronal generation. Alcohol Clin Exp Res 12:440-449.

Miller MW (1995) Effect of pre- or postnatal exposure to ethanol on the total number of neurons in the principal sensory nucleus of the trigeminal nerve: cell proliferation and neuronal death. Alcohol Clin Exp Res 19:1359-1363

Miller MW (1999) A longitudinal study of the effects of prenatal exposure on neuronal acquisition and death in the principal sensory nucleus of the trigeminal nerve: interaction with changes induced by transection of the infraorbital nerve. J Neurocytol 28:999-1015.

Miller MW (2003) Balance of cell proliferation and death among dynamic populations: a mathematical model. J Neurobiol 57:172-182.

Miller MW, Al-Ghoul WM (1993) Numbers of neurons in the developing principal sensory nucleus of the trigeminal nerve: enhanced survival of early-generated neurons over late-generated neurons. J Comp Neurol 330:491-501.

Miller MW, Kuhn PE (1997) Neonatal transection of the infraorbital nerve increases the expression of proteins related to neuronal death in the principal sensory nucleus of the trigeminal nerve. Brain Res 769:233-244.

Miller MW, Muller SJ (1989) Structure and histogenesis of the principal sensory nucleus of the trigeminal nerve: effects of prenatal exposure to ethanol. J Comp Neurol 282:570-580.

Miller MW, Nowakowski RS (1988) Use of bromodeoxyuridineimmunohistochemistry to examine the proliferation, migration and time of origin of cells in the central nervous system. Brain Res 457:44-52.

Miller MW, Nowakowski RS (1991) Effect of prenatal exposure to ethanol on the cell cycle kinetics and growth fraction in the proliferative zones of fetal rat cerebral cortex. Alcohol Clin Exp Res 15:229-232.

Mooney SM, Miller MW (1999) Effects of prenatal exposure to ethanol on systems matching: the number of neurons in the ventrobasal thalamic nucleus of the mature rat. Dev Brain Res 117:121-125.

Mooney SM, Miller MW (2000) Expression of bcl-2, bax, and caspase-3 in the CNS of the developing rat. Dev Brain Res 123:103-117.

Mullen RJ, Buck CR, Smith AM (1992) NeuN, a neuronal specific nuclear protein in vertebrates. Development 116:201-211.

Nornes HO, Morita M (1979) Time of origin of the neurons in the caudal brain stem of rat. Dev Neurosci 2:101-114.

Nowakowski RS, Lewin SB, Miller MW (1989) Bromodeoxyuridine immunohistochemical determination of the lengths of the cell cycle and the DNA-synthetic phase for an anatomically defined population. J Neurocytol 18:311-318.

Oppenheim RW (1991) Cell death during development of the nervous system. Rev Neurosci 14:453-501.

Paxinos G, Watson C (1982) The rat brain in stereotaxic coordinates. New York: Academic.

Pencea V, Bingaman KD, Wiegand SJ, Luskin MB (2001) Infusion of brainderived neurotrophic factor into the lateral ventricle of the adult rat leads to new neurons in the parenchyma of the striatum, septum, thalamus, and hypothalamus. J Neurosci 21:6706-6717.

Pitts AF, Miller MW (1995) Expression of nerve growth factor, p75, and trk in the somatosensory and motor cortices of mature rats: evidence for local trophic support circuits. Somatosens Mot Res 12:329-342.

Pitts AF, Miller MW (2000) Expression of nerve growth factor, brainderived neurotrophic factor, and neurotrophin-3 in the somatosensory cortex of the mature rat: coexpression with high-affinity neurotrophin receptors. J Comp Neurol 418:241-254. 
Rakic P (2002) Neurogenesis in adult primate neocortex: an evaluation of the evidence. Nat Rev Neurosci 3:65-71.

Schlaggar BL, O'Leary DD (1994) Early development of the somatotopic map and barrel patterning in rat somatosensory cortex. J Comp Neurol 346:80-96.

Schlaggar BL, De Carlos JA, O’Leary DD (1993) Acetylcholinesterase as an early marker of the differentiation of dorsal thalamus in embryonic rats. Dev Brain Res 75:19-30.

Schlessinger AR, Cowan WM, Gottlieb DI (1975) An autoradiographic study of the time of origin and the pattern of granule cell migration in the dentate gyrus of the rat. J Comp Neurol 159:149-175.

Schlessinger AR, Cowan WM, Swanson LW (1978) The time of origin of neurons in Ammon's horn and the associated retrohippocampal fields. Anat Embryol 154:153-173.

Scholzen T, Gerdes J (2000) The Ki-67 protein: from the known and the unknown. J Cell Physiol 182:311-322.

Siegenthaler JA, Miller MW (2004) Transforming growth factor $\beta 1$ modulates cell migration in rat cortex: effects of ethanol. Cereb Cortex 14:791-802.

Siegenthaler JA, Miller MW (2005) Transforming growth factor $\beta 1$ promotes cell cycle exit through the cyclin-dependent kinase inhibitor p21 in the developing cerebral cortex. J Neurosci 21:8627-8636.

Smolen AJ, Wright LL, Cunningham TJ (1983) Neuron numbers in the superior cervical sympathetic ganglion of the rat: a critical comparison of methods for cell counting. J Neurocytol 12:739-750.
Spreafico R, Frassoni C, Arcelli P, Battaglia G, Wenthold RJ, De Biasi S (1994) Distribution of AMPA selective glutamate receptors in the thalamus of adult rats and during postnatal development. A light and ultrastructural immunocytochemical study. Dev Brain Res 82:231-244.

Uziel D, Garcez P, Lent R, Peuckert C, Niehage R, Weth F. Bolz J (2006) Connecting thalamus and cortex: the role of ephrins. Anat Rec A Discov Mol Cell Evol Biol 288:135-142.

Vitalis T, Cases O, Gillies K, Hanoun N, Hamon M, Seif I, Gaspar P, Kind P, Price DJ (2002) Interactions between TrkB signaling and serotonin excess in the developing murine somatosensory cortex: a role in tangential and radial organization of thalamocortical axons. J Neurosci 22:4987-5000.

Wahle P, Di Cristo G, Schwerdtfeger G, Engelhardt M, Berardi N, Maffei L (2003) Differential effects of cortical neurotrophic factors on development of lateral geniculate nucleus and superior colliculus neurons: anterograde and retrograde actions. Development 130:611-622.

Waite PM, Li L, Ashwell KWS (1992) Developmental and lesion induced cell death in the rat ventrobasal complex. NeuroReport 3:485-488.

Wetts R, Herrup K (1983) Direct correlation between Purkinje and granule cell number in the cerebella of lurcher chimera and wild-type mice. Brain Res 312:41-47.

Wolf HK, Buslei R, Schmidt-Kastner R, Schmidt-Kastner PK, Pietsch T, Wiestler OD, Blumcke I (1996) NeuN: a useful neuronal marker for diagnostic histopathology. J Histochem Cytochem 44:1167-1171. 